\title{
Adsorption of $\mathrm{HO}_{x}$ on Aerosol Surfaces: Implications for the Atmosphere of Mars
}

\author{
A. D. ANBAR
}

Division of Geological and Planetary Sciences, California Institute of Technology, Pasadena

M-T. LEU

Earth and Space Sciences Division. Jet Propulsion Laboratory. California Institute of Technology, Pasadena

\author{
H. A. NAIR AND Y. L. YUNG \\ Division of Geological and Planetary Sciences, California Institute of Technology, Pasadena
}

\begin{abstract}
The potential impact of heterogeneous chemistry on the abundance and distribution of $\mathrm{HO}_{x}$ in the atmosphere of Mars has been assessed by combining observational data of dust and ice aerosol distributions with an updated photochemical model. Critical parameters include the altitude distributions of aerosols, and the surface loss coefficients $(\gamma)$ of $\mathrm{HO}_{2}$ on dust and ice in the lower atmosphere, and $\mathrm{H}$ on ice above $40 \mathrm{~km}$. We find that adsorption of $\mathrm{HO}_{2}$ on dust $\left(\gamma_{\mathrm{HO}_{2}} \geq 0.01\right)$, or ice near $30 \mathrm{~km}\left(\gamma_{\mathrm{HO}_{2}} \geq 0.1\right)$, can deplete $\mathrm{OH}$ abundances in the lower atmosphere by $10 \%$ or more. Such depletions approach those obtained by lowering the water vapor abundance by an order of magnitude below the global average observed by Viking $(\approx 25 \%)$. Since the oxidation of $\mathrm{CO}$ is catalyzed by $\mathrm{HO}_{x}$ in the lower atmosphere via the reaction $\mathrm{CO}+\mathrm{OH} \rightarrow \mathrm{CO}_{2}+\mathrm{H}$, loss of $\mathrm{OH}$ due to adsorption of $\mathrm{HO}_{2}$ on dust or ice at low altitudes could have a significant effect on the ratio $\mathrm{CO}: \mathrm{CO}_{2}$. The adsorption of $\mathrm{H}$ on ice at $50 \mathrm{~km}\left(\gamma_{\mathrm{H}}\right.$ $\geq 0.01$ ) can result in even larger $\mathrm{OH}$ depletions. However, this effect is localized to altitudes $>40 \mathrm{~km}$, where $\mathrm{CO}$ oxjdation is relatively unimportant. Laboratory data suggest that $\gamma_{\mathrm{HO}} \approx 0.01$ is a reasonable estimate for adsorption on dust. Larger values are plausible, but are not stongly supported by experimental evidence. The reactivity of $\mathrm{HO}_{2}$ on ice is unknown, while $\gamma_{H}$ on ice appears to be $<0.001$. There is a need for measurements of $\mathrm{HO}_{x}$ adsorption on surfaces representative of Martian aerosols at temperatures < $220 \mathrm{~K}$.
\end{abstract}

\section{INTRODUCTION}

Carbon dioxide comprises over $95 \%$ of the atmosphere of Mars, despite continuous photolysis of $\mathrm{CO}_{2}$ by solar $\mathrm{UV}$ radiation. Since the direct recombination of $\mathrm{CO}$ and $\mathrm{O}$ is slow, the balance between $\mathrm{CO}_{2}$ production and loss in the Martian atmosphere (the "stability of $\mathrm{CO}_{2}$ ") is thought to be maintained by a $\mathrm{HO}_{x}$-catalyzed $\mathrm{CO}$ oxidation scheme [McElroy and Donahue, 1972; Parkinson and Hunten, 1972]. Thus, the rate of CO oxidation is sensitive to the abundance and altitude-distribution of the $\mathrm{HO}_{x}$ species $(\mathrm{OH}, \mathrm{H}$ and $\mathrm{HO}_{2}$ ).

Recent models of gas-phase chemistry in the Martian atmosphere predict ratios of $\mathrm{CO}$ to $\mathrm{CO}_{2}$ lower than those observed, presumably due to an overabundance of $\mathrm{HO}_{x}$ [Shimazaki, 1989; Krasnopolsky, 1991; Nair et al., 1991,1992]. This is largely the result of two important factors which were not considered in the classic explanations of $\mathrm{CO}_{2}$ stability [McElroy and Donahue, 1972; Parkinson and Hunten, 1972]. First, the temperature dependence of the $\mathrm{CO}_{2} \mathrm{ab}$ sorption cross section [e.g., DeMore and Patapoff, 1972; Lewis and Carver, 1983] was not accounted for in earlier studies. This effect should decrease the calculated $\mathrm{CO}_{2}$ photolysis rate, while increasing the rate of $\mathrm{HO}_{x}$ production via photolysis of $\mathrm{H}_{2} \mathrm{O}$ [Parisot and Zucconi, 1984; Anbar et al., this issue]. Second, the water vapor profiles used in most of the earlier Mars models assumed that water was present primarily near the surface (the lower $5-10 \mathrm{~km}$ ). In current models, the lower atmosphere is considered well-mixed with respect to water to altitudes as high as $20-40 \mathrm{~km}$, consistent with observational data [Jakosky and Farmer, 1982; Clancy et al., 1992]. This increases the amount of $\mathrm{H}_{2} \mathrm{O}$ exposed to photolysis at higher altitudes, thereby raising the rate of $\mathrm{HO}_{x}$ production.

Copyright 1993 by the American Geophysical Union.
In a recent study which accounted for these factors, Shimazaki [1989] was able to balance $\mathrm{CO}_{2}$ production and loss only by imposing an upper limit on the water vapor abundance of 1-2 precipitable microns (prum). This constraint limits the abundance of $\mathrm{HO}_{x}$ species, which are largely derived from photolysis of $\mathrm{H}_{2} \mathrm{O}$. However, this water vapor abundance is an order of magnitude lower than the globally averaged abundance measured by Viking [Jakosky and Farmer, 1982], and is also substantially lower than the recent measurements of Clancy et al. [1992].

The adsorption of $\mathrm{HO}_{x}$ on aerosol surfaces is an alternative means of reducing $\mathrm{HO}_{x}$ abundances [Anbar et al., 1991; Krasnopolsky et al., 1991]. Most Martian atmospheric models have assumed that $\mathrm{HO}_{x}$ abundances are governed entirely by gas-phase chemistry [e.g., Yung et al., 1988; Shimazaki, 1989]. However, it is well established that reactive $\mathrm{HO}_{x}$ radicals are adsorbed by a wide variety of surfaces (Table 1). Adsorption of these species on the surfaces of Martian aerosols could decrease $\mathrm{HO}_{\boldsymbol{x}}$ abundances significantly, thereby retarding $\mathrm{CO}$ oxidation.

Previous discussions of the influence of heterogeneous chemistry on the Martian atmosphere have largely focussed on heterogeneous catalysis of CO oxidation [e.g., Clark, 1971; Huguenin et al., 1977; Atreya and Blamont, 1990; Leu et al., 1992], although surface catalyzed $\mathrm{CO}$ oxidation has not yet been observed under Martian atmospheric conditions. $\mathrm{HO}_{x}$ adsorption has typically been overlooked, although this phenomenon has been studied in the laboratory at temperatures and pressures approaching those of the lower Martian atmosphere (Table 1). Hunten [1974] was the first to suggest that "cold trapping" of water and $\mathrm{HO}_{x}$ species on surfaces could strongly perturb gas-phase $\mathrm{HO}_{x}$ catalytic chemistry. However, this was discussed as a low-temperature equilibrium condensation process, rather than as an adsorption reaction govemed by the kinetics of gas-surface reactions, capable of occurring at temperatures typical of the Martian surface and lower atmosphere. Kong and McElroy [1977] made the only attempt to quantitatively consider the impact of heterogeneous destruction of $\mathrm{HO}_{x}$, but consid- 
TABLE 1. Surface Loss Coefficients on Inorganic Oxides

\begin{tabular}{|c|c|c|c|}
\hline Surface & $\gamma$ & $T, K$ & Reference \\
\hline \multicolumn{4}{|c|}{ H Atom } \\
\hline $\mathrm{H}_{2} \mathrm{O}$ (s: amorphous) & $>\overline{0.1}$ & $<150$ & $1 *$ \\
\hline $\mathrm{K}_{2} \mathrm{CO}_{3}$ & 0.039 & 298 & 8 \\
\hline $\mathrm{NaNO}_{3}$ & 0.013 & 298 & 8 \\
\hline Pyrex & $6.0 \times 10^{-3}$ & 298 & 3 \\
\hline Quartz & $2.8 \times 10^{-3}$ & 298 & 3 \\
\hline $\mathrm{PbO}$ & $1.9 \times 10^{-3}$ & 298 & 2 \\
\hline $\mathrm{ZnO}$ & $1.2 \times 10^{-3}$ & 298 & 2 \\
\hline $\mathrm{Cr}_{2} \mathrm{O}_{3}$ & $1 \times 10^{-3}$ & 298 & 2 \\
\hline $\mathrm{H}_{2} \mathrm{O}(s)$ & $1.6 \times 10^{-4}$ & 253 & 4 \\
\hline $\mathrm{MgO}$ & $1 \times 10^{-4}$ & 298 & 2 \\
\hline $\mathrm{H}_{2} \mathrm{SO}_{4}$ & $\leq 5 \times 10^{-5}$ & 298 & 4 \\
\hline \multicolumn{4}{|c|}{ OH Radical } \\
\hline $\mathrm{H}_{2} \mathrm{SO}_{4}$ & 1 & 298 & 4 \\
\hline $\mathrm{H}_{2} \mathrm{O}(s)$ & $\geq 0.4$ & 250 & 4 \\
\hline $\mathrm{Fe}\left(\mathrm{NO}_{3}\right)_{3}-\mathrm{FeO}_{x}$ & 0.4 & 298 & 8 \\
\hline $\mathrm{Pb}\left(\mathrm{NO}_{3}\right)_{2}$ & 0.24 & 298 & 8 \\
\hline $\mathrm{Al}_{2} \mathrm{O}_{3}$ (on $\mathrm{Al}$ metal) & 0.10 & 250 & 4 \\
\hline $\mathrm{FeSO}_{4} \cdot \mathrm{nH}_{2} \mathrm{O}$ & 0.12 & 298 & 8 \\
\hline $\mathrm{H}_{2} \mathrm{SO}_{4}(28 \mathrm{wt} \%)$ & $>0.08$ & 249 & 5 \\
\hline $\mathrm{Zn}\left(\mathrm{NO}_{3}\right)_{3}$ & 0.045 & 298 & 8 \\
\hline $\mathrm{FeO}_{x}$ (on steel) & 0.04 & 250 & 4 \\
\hline $\mathrm{NaNO}_{3}$ & 0.036 & 298 & 8 \\
\hline Quartz & $6.3 \times 10^{-3}$ & 250 & 4 \\
\hline $\mathrm{H}_{2} \mathrm{O}(l)$ & $>3.5 \times 10^{-3}$ & 275 & 5 \\
\hline \multicolumn{4}{|c|}{$\mathrm{HO}_{2}$ Radical } \\
\hline $\mathrm{H}_{2} \mathrm{O}(l)$ & 0.2 & 298 & 7 \\
\hline $\mathrm{H}_{2} \mathrm{SO}_{4}(28$ wt.\%) & $>0.05$ & 249 & 5 \\
\hline $\mathrm{H}_{2} \mathrm{O}(l)$ & $>0.01$ & 275 & 5 \\
\hline Stainless Steel & $1.7 \times 10^{-2}$ & 320 & 6 \\
\hline Glass & $8 \times 10^{-3}$ & 298 & 6 \\
\hline $\mathrm{FeO}_{x}$ (on steel) & $3 \times 10^{-3}$ & 298 & 9 \\
\hline Quartz & $4 \times 10^{-3}$ & 298 & 6 \\
\hline
\end{tabular}

References: 1, Buch and Zhang [1991]; 2, Thrush [1965]; 3, Wood and Wise [1962]; 4, Gershenzon et al. [1986]; 5, Hanson et al. [1992]; 6, Gershenzon and Purmal [1990]; 7, Mozurkewich et al. [1987]; 8, Jech et al. [1982]; 9, Rozhenshtein et al. [1985].

Theoretical value.

ered only adsorption on the regolith at the Martian surface; reactions on aerosol surfaces (dust or ice) were not included, although the surface area available for reaction on aerosol particles in the Martian atmosphere is often comparable to the area of the planet's surface. Their study also did not account for the temperature-dependence of the $\mathrm{CO}_{2}$ absorption cross section, and assumed that water in the atmosphere was present only very close to the surface.

In this study, we explore the suggestion that the adsorption and reaction of $\mathrm{HO}_{x}$ on aerosol surfaces is an alternative mechanism for suppressing $\mathrm{HO}_{x}$ abundances and retarding the rate of $\mathrm{CO}$ oxidation, without violating observational constraints on the abundance of $\mathrm{H}_{2} \mathrm{O}$. Our intent is not to rigorously quantify the effects on $\mathrm{CO}$ chemistry, but to determine the feasibility of heterogeneous chemistry as a significant $\mathrm{HO}_{x}$-suppression mechanism. We assess the potential impact of heterogeneous processes involving the Martian surface, as well as dust and ice aerosols, on the abundance and altitude distributions of $\mathrm{HO}_{\mathrm{x}}$ species. The effects of these processes are compared to those of lowering the $\mathrm{H}_{2} \mathrm{O}$ abundance, and the implications for $\mathrm{CO}_{2}$ chemistry are discussed.

\section{MODEL DESCRIPTION}

The potential impact of $\mathrm{HO}_{x}$ adsorption was assessed by calculating $\mathrm{HO}_{x}$ altitude profiles in the presence of ice and/or dust using a one dimensional photochemical model, including transport. The
Caltech/Jet Propulsion Laboratory generalized planetary atmosphere photochemistry code is described elsewhere [Allen et al., 1981]. The model used here is a modified version of the model of Yung et al. [1988]. Details of this Mars model are described below.

\section{Heterogeneous Chemistry}

The rate of each $\mathrm{HO}_{x}$ adsorption reaction was set equal to the collision frequency of the reacting species with a surface, multiplied by a surface loss coefficient, $\gamma$, which represents the fraction of collisions which result in loss of the species from the gas phase $(0<\gamma<1)$. Published measurements of $\gamma$ for $\mathrm{HO}_{x}$ species are summarized in Table 1, and discussed further below. The collision frequency of a gas-phase species with an aerosol surface at a given altitude is a function of the mean thermal molecular speed $(v ; \mathrm{cm}$ $\left.\mathrm{s}^{-1}\right)$, and the surface area $\left(S ; \mathrm{cm}^{2} / \mathrm{cm}^{3}\right)$ available at that altitude, following the equation

$$
\text { Rate }\left(\mathrm{cm}^{-3} \mathrm{~s}^{-1}\right)=(1 / 4) \gamma S v N_{i},
$$

where $N_{i}\left(\mathrm{~cm}^{-3}\right)$ is the number density of the species being adsorbed [Michelangeli et al., 1991]. The temperatures used to calculate $v$ are described below. The dust and ice surfaces available for reaction in the model are plotted in Figure 1 as extinction coefficients $(\tau)$. For spherical particles, surface area and extinction coefficient are approximately related by $S=2 \tau$, assuming that the optical cross section is equal to twice the geometrical cross section.

For dust, the available surface area was calculated from dust distributions and particle dimensions supplied by D. Michelangeli, based on the work of Michelangeli et al. [in press]. An overall optical depth of approximately 0.2 was assumed; this represents a relatively clear Martian atmosphere, and does not simulate the much higher opacities observed during global dust storms. These data are similar to those obtained by Phobos 2 [Blamont et al., 1991]. We note that the total surface area available for reaction on these particles is comparable to the area of the planet's surface.

Persistent, geographically extensive detached hazes of water ice are common in the Martian atmosphere [e.g., Kahn, 1990]. Two different ice distribution profiles were included in this study, because these hazes have been observed over a range of altitudes. The first profile, based on data supplied by D. Michelangeli, reaches a maximum ice abundance at $30 \mathrm{~km}$. The second profile assumes the same distribution, but shifted $20 \mathrm{~km}$ higher to match observations by Phobos 2 [Blamont et al., 1991].

Once adsorbed, $\mathrm{HO}_{x}$ species are assumed to react with gas phase $\mathrm{OH}$ or $\mathrm{H}$, resulting in conversion to $\mathrm{H}_{2} \mathrm{O}$ or $\mathrm{H}_{2}$, which are rapidly returned to the gas phase. This mechanism is necessary to preserve mass balance and maintain the overall oxidation state of the atmos-

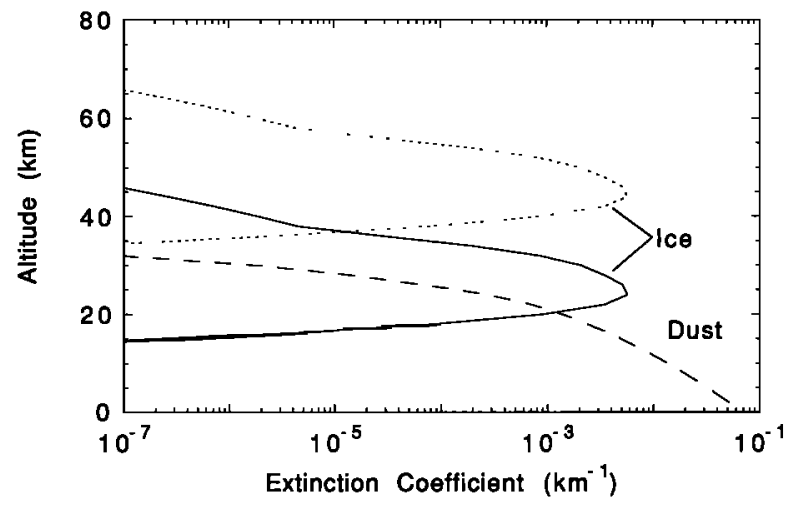

Fig. 1. Extinction coefficients of ice haze at $30 \mathrm{~km}$ (solid line), ice haze at $50 \mathrm{~km}$ (dotted line), and dust (dashed line). A total optical depth of $\approx 0.2$ due to dust is assumed. 
phere. For example, in the case of $\mathrm{HO}_{2}$ adsorption $\mathrm{H}$ and $\mathrm{OH}$ adsorption can be treated similarly), the surface chemistry is parameterized as

$$
\begin{array}{r}
\mathrm{HO}_{2}+\text { Surface } \rightarrow\left(\mathrm{HO}_{2}\right)_{3} \\
\left(\mathrm{HO}_{2}\right)_{3}+\mathrm{OH} \rightarrow \mathrm{H}_{2} \mathrm{O}+\mathrm{O}_{2} \\
\hline \text { Net: } \mathrm{HO}_{2}+\mathrm{OH} \rightarrow \mathrm{H}_{2} \mathrm{O}+\mathrm{O}_{2}
\end{array}
$$

where $\left(\mathrm{HO}_{2}\right)_{3}$ denotes the adsorbed species. At steady state, the rate of the net reaction must equal the rate of reaction (1). Thus, surface chemistry can be thought of as catalyzing the destruction of $\mathrm{HO}_{\boldsymbol{x}}$.

\section{Homogeneous Chemistry}

We have considered the gas phase chemistry of a $\mathrm{CO}_{2}-\mathrm{H}_{2} \mathrm{O}$ atmosphere. The continuity equation, including transport, was solved for the species $\mathrm{CO}_{2}, \mathrm{CO}, \mathrm{O}_{2}, \mathrm{O}, \mathrm{O}\left({ }^{1} \mathrm{D}\right), \mathrm{O}_{3}, \mathrm{H}_{2} \mathrm{O}, \mathrm{H}_{2} \mathrm{O}_{2}, \mathrm{OH}$, $\mathrm{HO}_{2}, \mathrm{H}_{2}$, and $\mathrm{H}$. The gas-phase reactions incorporated in the model and their rate constants are listed in Table 2 . Rate constants for three-body reactions were increased by a factor of two from the tabulated values to account for the efficiency of $\mathrm{CO}_{2}$ as a third body [Yung and DeMore, 1982].

\section{Boundary Conditions}

In our model calculations, the number densities of $\mathrm{O}_{2}, \mathrm{CO}$ and $\mathrm{CO}_{2}$ at $0 \mathrm{~km}$ were fixed to observed values $\left(2.34 \times 10^{14} \mathrm{~cm}^{-3}, 1.26\right.$ $\times 10^{14} \mathrm{~cm}^{-3}$, and $2.05 \times 10^{17} \mathrm{~cm}^{-3}$, respectively). The abundance of $\mathrm{H}_{2} \mathrm{O}$ was also fixed at the ground. Two $\mathrm{H}_{2} \mathrm{O}$ cases were modeled; one with an integrated column abundance of $16 \mathrm{pr} \mu \mathrm{m}$, and the other with $1.6 \mathrm{pr} \mu \mathrm{m}$. Following Shimazaki [1989], $\mathrm{H}_{2} \mathrm{O}$ was modeled as well-mixed up to a "critical altitude," above which saturation was

\begin{tabular}{|c|c|c|c|c|c|}
\hline & & eact & & Rate Coefficient" & Reference \\
\hline $\mathbf{R} \mathbf{a}$ & $\mathrm{O}_{2}+h v$ & $\rightarrow$ & 20 & $1.1 \times 10^{-7}$ & $\$$ \\
\hline R1b & & $\rightarrow$ & $O+O\left({ }^{1} D\right)$ & $6.8 \times 10^{-7}$ & $\$$ \\
\hline $\mathbf{R} 2 \mathbf{a}$ & $\mathrm{O}_{3}+h v$ & $\rightarrow$ & $\mathrm{O}_{2}+\mathrm{O}$ & $3.3 \times 10^{-4}$ & $\$$ \\
\hline R2b & & $\rightarrow$ & $\left.\mathrm{O}_{2}+\mathrm{O}^{\mathrm{l}} \mathrm{D}\right)$ & $2.1 \times 10^{-3}$ & $\S$ \\
\hline $\mathbf{R 3} \mathbf{a}$ & $\mathrm{H}_{2} \mathrm{O}+h v$ & $\rightarrow$ & $\mathrm{H}+\mathrm{OH}$ & $2.7 \times 10^{-6}$ & 8 \\
\hline $\mathbf{R} \mathbf{3} \mathbf{b}$ & & $\rightarrow$ & $\left.\mathrm{H}_{2}+\mathrm{O}^{1} \mathrm{D}\right)$ & $1.7 \times 10^{-7}$ & 8 \\
\hline R3c & & $\rightarrow$ & $2 \mathrm{H}+\mathrm{O}$ & $2.0 \times 10^{-7}$ & 1 \\
\hline R4 & $\mathrm{H}_{2} \mathrm{O}_{2}+h v$ & $\rightarrow$ & $2 \mathrm{OH}$ & $2.9 \times 10^{-5}$ & 8 \\
\hline R5a & $\mathrm{CO}_{2}+h v$ & $\rightarrow$ & $\mathrm{CO}+\mathrm{O}$ & $3.7 \times 10^{-7}$ & 8 \\
\hline R5b & & $\rightarrow$ & $C O+O\left({ }^{\prime} D\right)$ & $1.4 \times 10^{-7}$ & $\$$ \\
\hline R6 & $20+M$ & $\rightarrow$ & $\mathrm{O}_{2}+\mathrm{M}$ & $4.3 \times 10^{-28} T^{-2.00}$ & 1 \\
\hline R7 & $2 \mathrm{O}+\mathrm{O}_{2}$ & $\rightarrow$ & $\mathrm{O}_{3}+\mathrm{O}$ & $6.4 \times 10^{-35} e^{663 / T}$ & 2 \\
\hline R8 & $\mathrm{O}+\mathrm{O}_{2}+\mathrm{CO}_{2}$ & $\rightarrow$ & $\mathrm{O}_{3}+\mathrm{CO}_{2}$ & $5.0 \times 10^{-35} e^{724 / T}$ & 2 \\
\hline $\mathbf{R} 9$ & $\mathrm{O}+\mathrm{O}_{3}$ & $\rightarrow$ & $2 \mathrm{O}_{2}$ & $8.0 \times 10^{-12} e^{-2060 / T}$ & 3 \\
\hline R10 & $\mathrm{O}+\mathrm{CO}+\mathrm{M}$ & $\rightarrow$ & $\mathrm{CO}_{2}+\mathrm{M}$ & $6.5 \times 10^{-33} e^{-2184 / 7}$ & 4 \\
\hline R11 & $O^{\prime}(D)+O_{2}$ & $\rightarrow$ & $\mathrm{O}+\mathrm{O}_{2}$ & $3.2 \times 10^{-11} e^{70 / T}$ & 3 \\
\hline R12a & $\left.O^{\mathrm{l}} \mathrm{D}\right)+\mathrm{O}_{3}$ & $\rightarrow$ & $2 \mathrm{O}_{2}$ & $1.2 \times 10^{-10}$ & 3 \\
\hline R12b & & $\rightarrow$ & $\mathrm{O}_{2}+2 \mathrm{O}$ & $1.2 \times 10^{-10}$ & 3 \\
\hline R13 & $O\left({ }^{1} D\right)+H_{2}$ & $\rightarrow$ & $\mathrm{H}+\mathrm{OH}$ & $1.0 \times 10^{-10}$ & 3 \\
\hline R14 & $O\left({ }^{1} \mathrm{D}\right)+\mathrm{CO}_{2}$ & $\rightarrow$ & $\mathrm{O}+\mathrm{CO}_{2}$ & $7.4 \times 10^{-11} e^{120 / T}$ & 3 \\
\hline R15 & $O\left({ }^{l} D\right)+\mathrm{H}_{2} \mathrm{O}$ & $\rightarrow$ & $2 \mathrm{OH}$ & $2.2 \times 10^{-10}$ & 3 \\
\hline R16 & $2 \mathrm{H}+\mathrm{M}$ & $\rightarrow$ & $\mathrm{H}_{2}+\mathrm{M}$ & $1.5 \times 10^{-29} T^{-1.30}$ & 5 \\
\hline R17 & $\mathrm{H}+\mathrm{O}_{2}+\mathrm{M}$ & $\rightarrow$ & $\mathrm{HO}_{2}+\mathrm{M}$ & $\begin{array}{l}k_{o}=5.2 \times 10^{-28} T^{-160} \\
k_{\infty}=7.5 \times 10^{-11}\end{array}$ & 3 \\
\hline R18 & $\mathrm{H}+\mathrm{O}_{3}$ & $\rightarrow$ & $\mathrm{OH}+\mathrm{O}_{2}$ & $1.4 \times 10^{-10} e^{-470 / T}$ & 3 \\
\hline R19a & $\mathrm{H}+\mathrm{HO}_{2}$ & $\rightarrow$ & $2 \mathrm{OH}$ & $6.8 \times 10^{-11}$ & 6 \\
\hline R19b & & $\rightarrow$ & $\mathrm{H}_{2}+\mathrm{O}_{2}$ & $2.9 \times 10^{-12}$ & 6 \\
\hline R19c & & $\rightarrow$ & $\mathrm{H}_{2} \mathrm{O}+\mathrm{O}$ & $1.4 \times 10^{-12}$ & 6 \\
\hline $\mathbf{R} 20$ & $\mathrm{O}+\mathrm{H}_{2}$ & $\rightarrow$ & $\mathrm{OH}+\mathrm{H}$ & $1.6 \times 10^{-11} e^{-4570 / T}$ & 1 \\
\hline R21 & $\mathrm{O}+\mathrm{OH}$ & $\rightarrow$ & $\mathrm{O}_{2}+\mathrm{H}$ & $2.2 \times 10^{-11} e^{120 / T}$ & 3 \\
\hline R22 & $\mathrm{O}+\mathrm{HO}_{2}$ & $\rightarrow$ & $\mathrm{OH}+\mathrm{O}_{2}$ & $3.0 \times 10^{-11} e^{200 / T}$ & 3 \\
\hline R23 & $\mathrm{O}+\mathrm{H}_{2} \mathrm{O}_{2}$ & $\rightarrow$ & $\mathrm{OH}+\mathrm{HO}_{2}$ & $1.4 \times 10^{-12} e^{-2000 / T}$ & 3 \\
\hline R24 & $2 \mathrm{OH}$ & $\rightarrow$ & $\mathrm{H}_{2} \mathrm{O}+\mathrm{O}$ & $4.2 \times 10^{-12} e^{-240 / T}$ & 3 \\
\hline R25 & $2 \mathrm{OH}+\mathrm{M}$ & $\rightarrow$ & $\mathrm{H}_{2} \mathrm{O}_{2}+\mathrm{M}$ & $k_{0}=6.6 \times 10^{-29} T^{-0.80}$ & 3 \\
\hline & & & & $k_{\infty}=1.5 \times 10^{-11}$ & 3 \\
\hline R26 & $\mathrm{OH}+\mathrm{O}_{3}$ & $\rightarrow$ & $\mathrm{HO}_{2}+\mathrm{O}_{2}$ & $1.6 \times 10^{-12} e^{-940 / T}$ & 3 \\
\hline R27 & $\mathrm{OH}+\mathrm{H}_{2}$ & $\rightarrow$ & $\mathrm{H}_{2} \mathrm{O}+\mathrm{H}$ & $5.5 \times 10^{-12} e^{-2000 / T}$ & $\mathbf{3}$ \\
\hline $\mathbf{R} 28$ & $\mathrm{OH}+\mathrm{HO}_{2}$ & $\rightarrow$ & $\mathrm{H}_{2} \mathrm{O}+\mathrm{O}_{2}$ & $4.8 \times 10^{-11} e^{230 / T}$ & 3 \\
\hline R29 & $\mathrm{OH}+\mathrm{H}_{2} \mathrm{O}_{2}$ & $\rightarrow$ & $\mathrm{H}_{2} \mathrm{O}+\mathrm{HO}_{2}$ & $3.3 \times 10^{-12} e^{-200 / T}$ & 3 \\
\hline $\mathbf{R} 30$ & $\mathrm{OH}+\mathrm{CO}$ & $\rightarrow$ & $\mathrm{CO}_{2}+\mathrm{H}$ & $1.5 \times 10^{-13}\left(1+0.6 P_{a t m}\right)$ & 3 \\
\hline R31 & $\mathrm{HO}_{2}+\mathrm{O}_{3}$ & $\rightarrow$ & $\mathrm{OH}+2 \mathrm{O}_{2}$ & $1.1 \times 10^{-14} e^{-500 / T}$ & 3 \\
\hline $\mathbf{R} 32$ & $2 \mathrm{HO}_{2}$ & $\rightarrow$ & $\mathrm{H}_{2} \mathrm{O}_{2}+\mathrm{O}_{2}$ & $2.3 \times 10^{-13} e^{600 T}$ & 3 \\
\hline R33 & $2 \mathrm{HO}_{2}+\mathrm{M}$ & $\rightarrow$ & $\mathrm{H}_{2} \mathrm{O}_{2}+\mathrm{O}_{2}+\mathrm{M}$ & $1.7 \times 10^{-33} e^{1000 / T}$ & 3 \\
\hline
\end{tabular}
assumed. The height of the critical altitude is determined by the

TABLE 2. Gas-Phase Reactions in the Martian Atmosphere

References: 1, Hampson [1980]; 2, Lin and Leu [1982]; 3, Demore et al. [1990]; 4, Baulch et al. [1976]; 5, Tsang and Hampson [1986]; 6, Yung et al. [1988].

Cross sections used to calculate photodissociation rate constants for $\mathrm{CO}_{2}, \mathrm{O}_{2}$ and $\mathrm{H}_{2} \mathrm{O}$ are described in Anbar et al. [this issue]. Cross sections for $\mathrm{O}_{3}$ and $\mathrm{H}_{2} \mathrm{O}_{2}$ photodissociation calculations are similar to those used in $\mathrm{Yung}$ et al. [1988].

Units are $\mathrm{s}^{-1}$ for photolysis reactions, $\mathrm{cm}^{3} \mathrm{~s}^{-1}$ for two-body reactions, and $\mathrm{cm}^{6} \mathrm{~s}^{-1}$ for three-body reactions. Photolysis rate constants refer to the optically thin region. Reactions with $\mathrm{CO}_{2}$ as a third body have had their rate constants increased by a factor of two from the values given here. 
$\mathrm{H}_{2} \mathrm{O}$ column abundance. In our $16 \mathrm{pr} \mu \mathrm{m}$ and $1.6 \mathrm{pr} \mu \mathrm{m}$ models, the critical heights were $\approx 20 \mathrm{~km}$ and $35 \mathrm{~km}$, respectively. The two $\mathrm{H}_{2} \mathrm{O}$ profiles, shown in Figure 2, are in agreement with those of Shimazaki [1989] below $50 \mathrm{~km}$, but are somewhat larger at higher altitudes.

Following Yung et al. [1988], the escape velocities of $\mathrm{H}$ and $\mathrm{H}_{2}$ were fixed to $6.76 \times 10^{3} \mathrm{~cm} \mathrm{~s}^{-1}$ and $1.70 \times 10^{2} \mathrm{~cm} \mathrm{~s}^{-1}$. The $O$ escape flux was set to $6 \times 10^{7} \mathrm{~cm}^{-2} \mathrm{~s}^{-1}$, in agreement with McElroy [1972].

\section{Other Input Parameters}

The eddy diffusivity profile in the Martian atmosphere is uncertian, and has been the subject of some debate [e.g., Kong and McElroy, 1977; Kahn, 1990; Atreya and Blamont, 1990]. Our results should be insensitive to this profile, over the range of values that has been suggested. This is due to the exceedingly short lifetimes of the $\mathrm{HO}_{x}$ species relative to the transport timescale. At the ground, the lifetime of the $\mathrm{HO}_{x}$ family is on the order of $\left[\mathrm{HO}_{x}\right] / k_{28}[\mathrm{OH}]\left[\mathrm{HO}_{2}\right] \approx 10^{4} \mathrm{~s}$, while the transport timescale can be approximated by $\mathrm{H}^{2} / K_{z}$ ( $\mathrm{H}$ is atmospheric scale height; $K_{z}$ is eddy diffusivity) $\approx 10^{12} / 10^{5}=10^{7} \mathrm{~s}$. Therefore, the $\mathrm{HO}_{x}$ family is in a state of photochemical equilibrium. The abundances of longerlived species (e.g., $\mathrm{CO}$ and $\mathrm{O}_{2}$ ) which could be impacted by different eddy diffusivity profiles, and hence affect the partitioning of the $\mathrm{HO}_{x}$ species, have been fixed to observed values. Thus, the distribution of the $\mathrm{HO}_{x}$ species should be independent of the choice of the eddy diffusion profile. The eddy diffusion coefficients used in this model grade exponentially from $10^{5} \mathrm{~cm}^{2} \mathrm{~s}^{-1}$ at the surface to $5 \times 10^{7} \mathrm{~cm}^{2} \mathrm{~s}^{-1}$ at $100 \mathrm{~km}$, and remain constant at higher altitudes. This is similar to Shimazaki's [1989] profile $A$.

The COSPAR temperature profile has been adopted below 100 $\mathrm{km}$ [Seiff. 1982], with an exospheric temperature of $365 \mathrm{~K}$ [Kong and McElroy, 1977]. The temperature profile of the upper atmosphere was then found by fitting a spline curve to these data.

Solar flux values at $1 \mathrm{AU}$ were obtained from Mount and Rottman [1983] and Torr and Torr [1985], and scaled to 1.52 AU. The cross sections used to calculate photodissociation rate constants are described in Anbar et al. [this issue] and Yung et al. [1988]. $\mathrm{CO}_{2}$ cross sections were adopted from Lewis and Carver [1983], and the temperature dependence of $\mathrm{CO}_{2}$ absorption was modeled following the procedure of Anbar et al. [this issue]. No adjustment was made for aerosol scattering or absorption in the results presented below. We find that incorporation of these effects into the model changes photolytic rate constants by a maximum amount of $10-20 \%$ at the ground. The magnitude of this effect decreases with increasing altitude. Since the bulk of $\mathrm{HO}_{x}$ formation occurs near $20 \mathrm{~km}$, and since $\mathrm{HO}_{x}$ lifetimes are very short with respect to transport times-

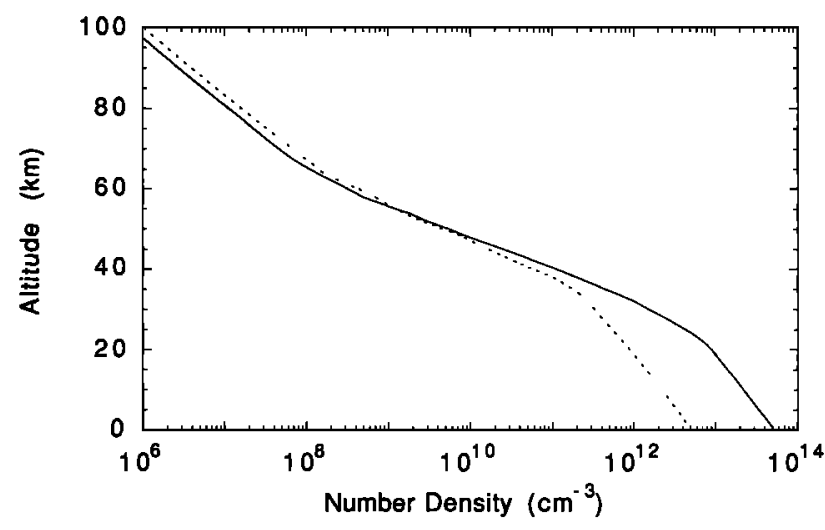

Fig. 2. $\mathrm{H}_{2} \mathrm{O}$ profiles corresponding to globally averaged water vapor abundances of 16 prum (solid line) and 1.6 prum (dotted line). cales, aerosol effects on the radiation field should not have much impact on our results. All computations employed a diumally averaged radiation field at equinox for $\approx 30^{\circ}$ latitude.

\section{MODEL RESULTS}

$\mathrm{HO}_{x}$ profiles were calculated for a number of different models (Table 3), and the results are summarized in Figures 3-6. Models A and $B$ (Figure 3 ) invoke no heterogeneous chemistry, but assume water vapor abundances of 16 and $1.6 \mathrm{pr} \mu \mathrm{m}$, respectively. The results of model B are close to those of Shimazaki [1989], who also assumed $\approx 1 \mathrm{pr} \mu \mathrm{m} \mathrm{H}_{2} \mathrm{O}$. The depletions of $\mathrm{HO}_{2}, \mathrm{H}$ and $\mathrm{OH}$ in model $\mathrm{B}$ relative to model $\mathrm{A}$ are largest in the lower atmosphere (below 50 $\mathrm{km}$ ), since the largest differences in water vapor abundances occur near the surface (Figure 2), and the chemical loss timescales for these species dominate over transport timescales. The abundances of $\mathrm{OH}$ and $\mathrm{HO}_{2}$ are most strongly affected; their column densities are depleted by $\approx 25 \%$ and $\approx 65 \%$, respectively. Significantly, in both models, $\mathrm{HO}_{2}$ is the dominant $\mathrm{HO}_{x}$ species between the ground and $\approx 35 \mathrm{~km}$, which is where most of the dust surface area is available. This is also where most of the ice surface is available in the low-altitude ice haze case we have considered (Figure 1). At higher altitudes, where the ice abundance may exceed that of dust (Figure 1), $\mathrm{H}$ is the primary $\mathrm{HO}_{x}$ species. Thus, the influence of $\mathrm{HO}_{x}$ adsorption is determined by the rate of adsorption of $\mathrm{HO}_{2}$ on dust and regolith, and on low-altitude ice, and of $\mathrm{H}$ on ice at higher altitudes; the rate of adsorption of $\mathrm{OH}$ on either surface is insignificant by comparison. Due to the reactions which relate the $\mathrm{HO}_{\boldsymbol{x}}$ radicals to one another, heterogeneous loss of one of these radicals propagates through the entire $\mathrm{HO}_{x}$ family.

Heterogeneous chemistry was incorporated in models $\mathrm{Cl}, \mathrm{C2}, \mathrm{C3}$, D1, D2, E1, E2 and E3, all of which assumed $16 \mathrm{pr} \mu \mathrm{m}$ of water vapor. Adsorption on dust and on the surface ( $\mathrm{Cl}, \mathrm{C} 2$ and $\mathrm{C} 3)$ was considered separately from adsorption on ice (D1, D2, E1, E2 and E3) to allow the effects of reactions on different surfaces to be distinguished. In models $\mathrm{C1}, \mathrm{C2}, \mathrm{C} 3, \mathrm{D} 1$ and D2, only $\mathrm{HO}_{2}$ adsorption was considered. Models E1, E2 and E3 include only $\mathrm{H}$ adsorption. Since gas-phase $\mathrm{HO}_{x}$ catalyzed $\mathrm{CO}$ oxidation is most rapid below $40 \mathrm{~km}$ [e.g., Kong and McElroy, 1977; Shimazaki, 1989], the impact of heterogeneous $\mathrm{HO}_{x}$ depletion on $\mathrm{CO}$ chemistry can be assessed to first order by comparing the $\mathrm{HO}_{x}$ altitude distributions to this $40 \mathrm{~km}$ "threshhold." The abundance of $\mathrm{OH}$ is particularly critical, since the rate of $\mathrm{CO}$ oxidation is limited by the rate of $\mathrm{R} 30$ $\left(\mathrm{CO}+\mathrm{OH} \rightarrow \mathrm{CO}_{2}+\mathrm{H}_{2} \mathrm{O}\right.$ ).

Examination of the $\mathrm{C}$ models (Figure 4) reveals that adsorption of $\mathrm{HO}_{2}$ on dust can significantly deplete some $\mathrm{HO}_{x}$ species in the lower atmosphere, even for $\gamma_{\mathrm{HO}_{2}}=0.001$ (model C1). If $\gamma_{\mathrm{HO}_{2}}=0.01$, the total $\mathrm{HO}_{x}$ budget in model $\mathrm{C} 2$ approaches that of the $1.6 \mathrm{pr} \mu \mathrm{m}$ water vapor case (model $B$ ). Although the abundance of $\mathrm{OH}$ is only reduced by $\approx 10 \%$ on a column-integrated basis (Table 3 ), the bulk of this reduction occurs below $20 \mathrm{~km}$, where the rate of $\mathrm{HO}_{x}$-catalyzed CO recombination is highest when heterogeneous chemistry is not included. Thus, the rate of $\mathrm{CO}$ recombination may be retarded substantially by adsorption of $\mathrm{HO}_{2}$ on dust, with $\mathrm{rHO}_{2}=0.01$. If an even larger surface loss coefficient is considered $\left(\gamma_{\mathrm{HO}_{2}}=0.1\right.$; model C3), then the total $\mathrm{HO}_{x}$ abundance is actually lowered below that of model B, and the $\mathrm{OH}$ abundance comes within $25 \%$ of model $\mathrm{B}$. The plausibility of these values of $\gamma$ is assessed below.

Adsorption of $\mathrm{HO}_{2}$ on ice particles centered at $30 \mathrm{~km}$ was considered in models D1 and D2 (Figure 5), while adsorption of $\mathrm{H}$ on a haze at $50 \mathrm{~km}$ was considered in models E1, E2 and E3 (Figure 6). Adsorbed $\mathrm{H}$ was assumed to react with gas-phase $\mathrm{H}$ to produce $\mathrm{H}_{2}$ gas, by analogy with the $\mathrm{HO}_{2}$ surface chemistry described earlier. The influence of ice surfaces on $\mathrm{HO}_{x}$ abundances, as 
TABLE 3. Summary of Model Results: $\mathrm{HO}_{x}$ Column Abundances

\begin{tabular}{|c|c|c|c|c|c|c|c|}
\hline Model & $\begin{array}{l}\mathrm{H}_{2} \mathrm{O} \\
\text { prum }\end{array}$ & Surfaces & $\boldsymbol{\gamma}$ & $\begin{array}{c}H \\
\times 10^{14}\end{array}$ & $\begin{array}{c}\mathrm{OH} \\
\times 10^{12}\end{array}$ & $\begin{array}{r}\mathrm{HO}_{2} \\
\times 10^{14}\end{array}$ & $\begin{array}{l}2 \mathrm{HO}_{\mathrm{x}} \\
\times 10^{14}\end{array}$ \\
\hline $\mathbf{A}$ & 16 & - & - & 2.58 & 1.20 & 5.05 & 7.64 \\
\hline $\mathbf{B}$ & 1.6 & - & - & 2.51 & 0.88 & 1.74 & 4.25 \\
\hline $\mathbf{C l}$ & 16 & Dust and Regolith & $n_{\mathrm{HO}_{2}}=0.001$ & 2.58 & 1.17 & 4.56 & 7.15 \\
\hline C2 & 16 & Dust and Regolith & $\gamma_{\mathrm{HO}_{2}}=0.01$ & 2.52 & 1.10 & 3.20 & 5.75 \\
\hline C3 & 16 & Dust and Regolith & $\mathrm{rHO}_{2}=0.1$ & 2.36 & 1.00 & 1.76 & 4.13 \\
\hline D1 & 16 & Ice at $30 \mathrm{~km}$ & $\mathrm{rHO}_{2}=0.01$ & 2.58 & 1.19 & 4.98 & 7.57 \\
\hline D2 & 16 & Ice at $30 \mathrm{~km}$ & $\gamma_{\mathrm{HO}_{2}}=0.1$ & 2.48 & 1.08 & 4.45 & 6.94 \\
\hline E1 & 16 & Ice at $50 \mathrm{~km}$ & $\gamma_{H}=0.001$ & 2.30 & 1.11 & 5.06 & 7.37 \\
\hline E2 & 16 & Ice at $50 \mathrm{~km}$ & $\gamma_{H}=0.01$ & 1.21 & 0.86 & 5.03 & 6.25 \\
\hline $\mathbf{E 3}$ & 16 & Ice at $50 \mathrm{~km}$ & $\gamma_{H}=0.1$ & 0.71 & 0.74 & 5.01 & 5.72 \\
\hline
\end{tabular}

Abundances of $\mathrm{H}, \mathrm{OH}, \mathrm{HO}_{2}$ and $\mathrm{\Sigma} \mathrm{HO}_{x}$ reported as $\mathrm{cm}^{-2}$

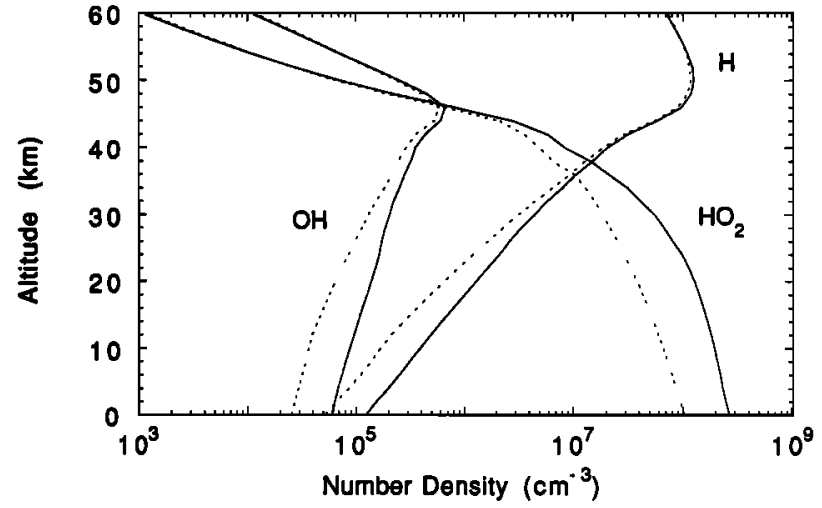

Fig. 3. Distribution of $\mathrm{HO}_{x}$ species calculated for model A (solid line) and model B (dotted line).

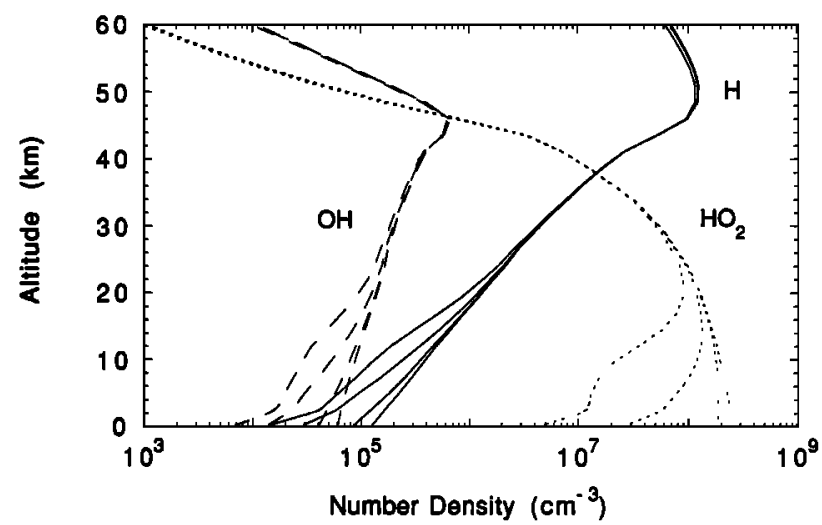

Fig. 4. Distribution of $\mathrm{HO}_{2}$ (dotted line), $\mathrm{H}$ (solid line), and $\mathrm{OH}$ (dashed line) in models $\mathrm{A}, \mathrm{Cl}, \mathrm{C2}$, and C3. The highest abundances for all three species are those of model $A$. Abundances decrease as $\gamma_{\mathrm{HO}}$ increases from 0.001 (model C1) to 0.1 (model C3). A water vapor abundance of $16 \mathrm{prum}$ is assumed.

expected, is very sensitive to the altitude of the ice cloud. When the ice distribution is centered at $30 \mathrm{~km}$ and $\gamma_{\mathrm{HO}_{2}}=0.01$ (model DI), only a very small impact on $\mathrm{HO}_{x}$ is seen in the lower atmosphere. Values of $\gamma_{\mathrm{HO}_{2}}$ on the order of 0.1 (model D2) are necessary to achieve an $\mathrm{OH}$ abundance comparable to that of model C2. Even higher values would be necessary to approach the depletions found in the case of low water abundance (model B). The inclusion of $\mathrm{H}$ adsorption on ice in the lower atmosphere was found to have little effect on $\mathrm{HO}_{x}$ abundances.

If the ice distribution maximum is shifted to $\approx 50 \mathrm{~km}$ (models El, $\mathrm{E} 2$ and E3), the predicted abundances of $\mathrm{H}$ and $\mathrm{OH}$ are substantially smaller than in the $30 \mathrm{~km}$ cases utilizing comparable values of $\gamma$ (e.g. compare models D1 and E2, or D2 and E3). Even if $\gamma_{H}=0.001$ (model $\mathrm{El}$ ), $\mathrm{OH}$ is depleted by nearly $10 \%$ relative to model $\mathrm{A}$. The sensitivity to the altitude distribution of the ice particles is due largely to the fact that, in the purely gas-phase case, the chemical loss timescale of $\mathrm{OH}$ (and, hence, its abundance) has a maximum near $50 \mathrm{~km}$. Thus, the introduction of a heterogeneous loss process has its greatest effect on $\mathrm{OH}$ at this altitude.

Of all the heterogeneous cases studies, models E2 and E3 have the largest impact on the $\mathrm{OH}$ abundance, resulting in even lower

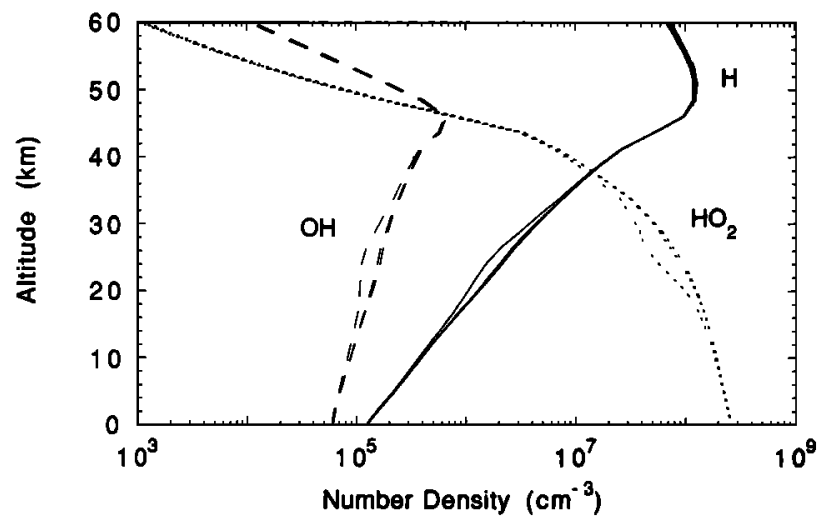

Fig. S. Distribution of $\mathrm{HO}_{2}$ (dotted line), $\mathrm{H}$ (solid line) and $\mathrm{OH}$ (dashed line) in models $A, D 1$, and $D 2$. The highest abundances for all three species are those of model A. Abundances decrease as $\gamma_{\mathrm{HO}_{2}}$ increases from 0.01 (model D1) to 0.1 (model D2). A water vapor abundance of $16 \mathrm{prum}$ is assumed.

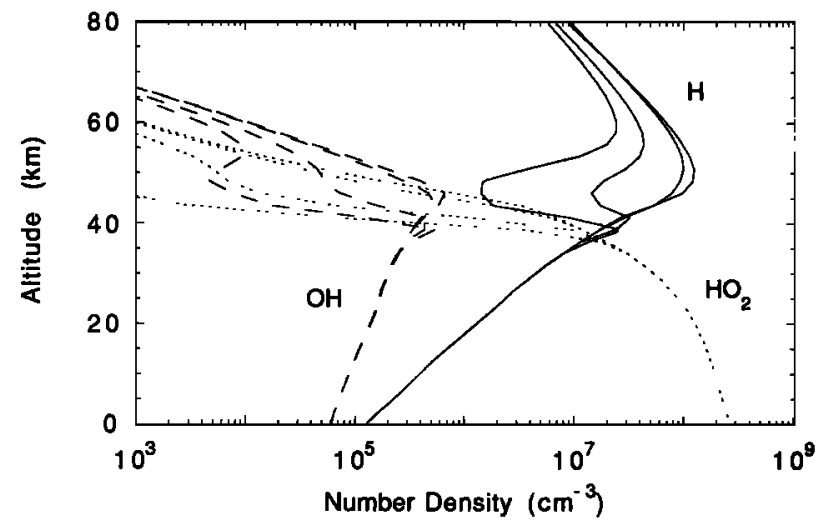

Fig. 6. Distribution of $\mathrm{HO}_{2}$ (dotted line), $\mathrm{H}$ (solid line), and $\mathrm{OH}$ (dashed line) in models A, E1, E2, and E2. The highest abundances for all three species are those of model $A$. Abundances decrease as $\gamma_{H}$ increases from 0.001 (model E1) to 0.1 (model E3). A water vapor abundance of $16 \mathrm{prum}$ is assumed. 
abundances than in model B. However, due to the ice particle distribution, this depletion occurs primarily above $40 \mathrm{~km}$ (Figure 5), where the rate of $\mathrm{HO}_{x}$-catalyzed $\mathrm{CO}$ recombination is quite low [e.g., Kong and McElroy, 1977; Shimazaki, 1989]. Thus, heterogeneous processes on ice surfaces at these altitudes are likely to have only a small effect on $\mathrm{CO}_{2}$ stability.

\section{COMPARISONS WITH LABORATORY ADSORPTION DATA}

The plausibility of the range of $\gamma$ values described above can only be assessed by making comparisons to laboratory data. Unfortunately, the number of studies of $\mathrm{HO}_{x}$ adsorption is small, and most surfaces that have been studied are not directly relevant to the Martian surface or aerosols. They are, at best, crude analogs of the reactive surfaces available on Mars, which are likely to be composed of complex, iron-rich oxide and silicate weathering products of basalts [e.g., Bell et al., 1990; Morris et al., 1990; Pinet and Chevrel, 1990]. Nonetheless, we believe the published data are useful to provide order-of-magnitude estimates of $\gamma$.

Table 1 summarizes the published values of $\mathrm{HO}_{x}$ surface loss coefficients on inorganic oxides. $\mathrm{HO}_{\boldsymbol{x}}$ adsorption data on metal surfaces have not been included, although these tend to be substantially larger than the values on oxides [e.g., Thrush, 1965]. We have also omitted data from early studies which indicate relatively large values of $\gamma_{\mathrm{HO}_{x}}$ on oxide surfaces [e.g., Smith, 1943]; we are not confident of the reliability of these early measurements.

Most data were collected at or near room temperature. At lower temperatures, it is expected that $\gamma$ should increase. This can be understood if the data represent an equilibrium between an energetically favorable adsorption reaction, and an endothermic desorption process. Such behavior has been observed for $\mathrm{OH}$ and $\mathrm{HO}_{2}$ on $\mathrm{H}_{3} \mathrm{PO}_{4}$, where loss coefficients increase by an order of magnitude as temperature is lowered from $298 \mathrm{~K}$ to $220 \mathrm{~K}$ [Margitan, 1976; Howard, 1979]. This observation is of special importance to the Martian atmosphere, where typical temperatures are $<220 \mathrm{~K}$.

The $\mathrm{HO}_{2}$ data demonstrate that a $\gamma_{\mathrm{HO}_{2}}$ value $>0.001$ is entirely consistent with the few studies that have been done. A value of 0.01 on potential Martian surfaces is plausible if temperature effects are considered (see above). This conclusion is strengthened if the $\mathrm{OH}$ data are considered. Although adsorption of $\mathrm{OH}$ is probably not an important $\mathrm{HO}_{x}$ sink in the Martian atmosphere, we include these data because $\mathrm{OH}$ and $\mathrm{HO}_{2}$ have similar affinities for many surfaces [Jech et al., 1982]; in Table $1, \gamma_{\mathrm{OH}}$ and $\gamma_{\mathrm{HO}_{2}}$ are typically within an order of magnitude of each other for comparable surfaces. Moreover, the $\mathrm{OH}$ data are the most comprehensive, since they cover a variety of complex oxides, including some containing iron. If the OH data are used to supplement the $\mathrm{HO}_{2}$ data by inference, then $\gamma_{\mathrm{HO}_{2}} \approx 0.01$ seems a reasonable estimate for adsorption on Martian dust and regolith, particularly at low temperatures. Higher values of $\gamma$ are possible, but are not well supported by the laboratory data. The adsorption affinity of $\mathrm{HO}_{2}$ for ice is unknown, but is likely to be $\geq 0.01$ on the basis of comparison with data for adsorption on liquid water, as well as the $\mathrm{OH}$ data. A value as high as $\gamma_{\mathrm{HO}_{2}} \approx 0.1$ is plausible.

The adsorption of $\mathrm{H}$ on ice is more problematic. The only laboratory study indicates $\gamma_{\mathrm{H}}<0.001$ [Gershenzon et al., 1986], which is too small for an appreciable effect in the atmosphere. However, a theoretical study of adsorption on amorphous ice suggests $\gamma_{\mathrm{H}}>0.1$ at $<150 \mathrm{~K}$ [Buch and Zhang, 1991]. The applicability of this result to Martian ice surfaces is doubtful, since typical Martian atmospheric temperatures are higher than those at which amorphous ice is stable. Thus, the adsorption of $\mathrm{H}$ is unlikely to be an important process.

\section{DISCUSSION AND CONCLUSIONS}

Our findings indicate that heterogeneous chemistry on aerosols is capable of lowering the abundance of $\mathrm{HO}_{x}$ species in the Martian atmosphere. Adsorption of $\mathrm{HO}_{2}$ on either dust or ice surfaces below $40 \mathrm{~km}$ could have a non-trivial impact on the abundance of $\mathrm{HO}_{x}$, and hence on the ratio of $\mathrm{CO}: \mathrm{CO}_{2}$; the predicted depletions of $\mathrm{OH}$ ( $\approx 10 \%$ or more) approach those achieved by lowering the $\mathrm{H}_{2} \mathrm{O}$ abundance from 16 pr $\mu \mathrm{m}$ to 1.6 prum $(\approx 25 \%)$, which could significantly retard the rate of $\mathrm{CO}$ oxidation. The $\gamma$ values required for such an effect $\left(\gamma_{\mathrm{HO}_{2}} \geq 0.01\right.$ on dust; $\gamma_{\mathrm{HO}_{2}} \geq 0.1$ on ice) are not unreasonable when compared to the few laboratory data available. However, there is a clear need for laboratory experiments on surfaces representative of Martian aerosols, and at temperatures approaching those of the lower Martian atmosphere.

Adsorption of $\mathrm{H}$ on ice near $50 \mathrm{~km}$ altitude can also result in substantial $\mathrm{HO}_{x}$ depletions, if $\gamma_{\mathrm{H}} \geq 0.01$. However, these depletions are confined to altitudes at which the rate of $\mathrm{HO}_{x}$-catalyzed $\mathrm{CO}$ oxidation is already low. Additionally, these values of $\gamma_{H}$ are higher than observed in the only relevant laboratory study. Thus, little impact on the chemistry of $\mathrm{CO}$ is expected from $\mathrm{H}$ adsorption on ice.

While this study has demonstrated the potential influence of heterogeneous chemistry, a critical re-examination of Martian atmospheric chemistry is required to rigorously quantify the importance of such reactions. For example, the uncertainties associated with some of the rate constants used in this model are as large as $\pm 30 \%$ at room temperature, with somewhat higher uncertainties at Martian temperatures. Thus, it may be possible to reduce the abundance of $\mathrm{HO}_{x}$ radicals in the modeled atmosphere by manipulating key rate constants within the reported uncertainties. The abundance of $\mathrm{HO}_{x}$ is controlled by the rate of production, via $\mathrm{H}_{2} \mathrm{O}$ photolysis with a contribution from $\left.\mathrm{O}^{1} \mathrm{D}\right)+\mathrm{H}_{2} \mathrm{O} \rightarrow 2 \mathrm{OH}(\mathrm{R} 15)$ at the surface, and the rate of loss, dominated by the reaction $\mathrm{OH}+$ $\mathrm{HO}_{2} \rightarrow \mathrm{H}_{2} \mathrm{O}+\mathrm{O}_{2}$ (R28). Thus, the abundance of $\mathrm{HO}_{x}$ can be decreased by decreasing the production rate $\left(\mathrm{R} 3 \mathrm{a}+\mathrm{K} 15\left[\mathrm{O}\left({ }^{\mathrm{D}} \mathrm{D}\right)\right]\right)$ $\left[\mathrm{H}_{2} \mathrm{O}\right]$, increasing the rate constant $\mathrm{K} 28$, or a combination of these changes. The impact of reasonable "re-evaluations" of these gasphase data must be quantified.

Additionally, reactions involving $\mathrm{HO}_{x}$ are considered critical to many processes in the Martian atmosphere (e.g., the abundance of $\mathrm{O}_{3}$, the escape rate of $\mathrm{H}$, and the coupling of $\mathrm{H}$ escape to $\mathrm{O}$ escape). If $\mathrm{HO}_{x}$ abundances must be suppressed, we may need to revise our explanations of the chemistry governing such processes. For example, although it is generally assumed that $\mathrm{O}_{3}$ loss is dominated by reaction with $\mathrm{HO}_{x}$ [e.g., Lindner, 1988], catalytic $\mathrm{NO}_{x}$ chemistry may become important if $\mathrm{HO}_{x}$ levels are depressed. Hence, the photochemistry of nitrogen [Yung et al., 1977] should be re-examined in light of this work.

It must be realized that the inclusion of heterogeneous $\mathrm{HO}_{x}$ chemistry introduces a complicated variable into Martian atmospheric modeling, since the altitude distributions of $\mathrm{H}, \mathrm{OH}$ and $\mathrm{HO}_{2}$ are sensitive to the altitude distribution of the aerosol surfaces (compare models C2,D1, and E2). Like the water vapor abundance, the altitude distribution of aerosol surfaces (especially ice surfaces) varies latitudinally, seasonally and diumally. Thus, heterogeneous $\mathrm{HO}_{x}$ chemistry must be introduced with care, and should not be used to "solve" modeling difficulties until all the reasonable permutations of gas-phase chemistry have been explored. Despite this caveat, the importance of quantifying the role of heterogeneous chemistry in the atmosphere of Mars cannot be overlooked. In the comparative planetology of atmospheres, Mars is said to possess the "dustiest" atmosphere. The impact of aerosols on Martian atmos- 
pheric chemistry is largely unknown, despite some imaginative but unproven speculations [Huguenin, et al. 1977; Atreya and Blamont, 1990]. This study has combined laboratory data and photochemical modeling to demonstrate that heterogeneous chemistry could be important in regulating the abundance of $\mathrm{HO}_{x}$. This opens the exciting possibility that the Martian atmosphere may be a natural laboratory for the quantitative study of heterogeneous reactions, which are now considered important in the terrestrial atmosphere [Molina et al., 1987; Tolbert et al., 1988; Leu, 1988; Michelangeli et al., 1991].

Acknowledgments. The authors thank D. Michelangeli for providing aerosol data in electronic format. The assistance of $\mathrm{M}$. Allen was greatly appreciated. The comments of two anonymous reviewers were extremely helpful. This research was supported by NASA grant NAGW-2204. Division of Geological Sciences, Califomia Institute of Technology, contribution 5114.

\section{REFERENCES}

Allen, M., Y. L. Yung, and J. W. Waters, Vertical transport and photochemistry in the terrestrial mesosphere and lower thermosphere, J. Geophys. Res., 86, 3617-3627, 1981.

Anbar, A. D., M-T. Leu, and Y. L. Yung, The adsorption of $\mathrm{HO}_{x}$ on aerosol surfaces: Implications for the stability of $\mathrm{CO}_{2}$ in the atmosphere of Mars, Bull. Am. Astron. Soc., 23, 1212, 1991.

Anbar, A. D., H. A. Nair, and M. Allen, Photodissociation in the atmosphere of Mars: Impact of high-resolution, temperature-dependent $\mathrm{CO}_{2}$ cross-section measurements, J. Geophys. Res., this issue.

Atreya, S. K., and J. E. Blamont, Stability of the Martian atmosphere: Possible role of heterogeneous chemistry, Geophys. Res. Lett., 17, 287$290,1990$.

Baulch, D. L., D. D. Drysdale, J. Duxbury, and S. J. Grant, Evaluated Kinetic Data for High Temperature Reactions: Homogeneous Gas Phase Reactions of the $\mathrm{O}_{2} \mathrm{O}_{3}$ System, the $\mathrm{CO}_{2}-\mathrm{O}_{2}-\mathrm{H}_{2}$ System, and of Sulphur-Containing Species, Butterworths, London, 1976.

Bell, J. F., III, T. B. McCord, and P. D. Owensby, Observational evidence of crystalline iron oxides on Mars, $J$. Geophys. Res., 95, 14,447-14,461, 1990.

Blamont, J. E., E. Chassefière, J. P. Goutail, B. Mege, M. Nunes-Pinharanda, G. Souchon, V. A. Krasnopolsky, A. A. Krysko, and V. I. Moroz, Vertical profiles of dust and ozone in the Martian atmosphere deduced from solar occultation measurements, Planet. Space Sci., 39, 175-187, 1991.

Buch, V., and $Q$. Zhang, Sticking probability of $H$ and $D$ atoms on amorphous ice: A computational study, Astrophys. J., 379, 647-652, 1991.

Clancy, R. T., A. W. Grossman, and D. O. Muhleman, Mapping Mars water vapor with the Very Large Array, Icarus, 100, 48-59, 1992.

Clark, I. D., The chemical kinetics of $\mathrm{CO}_{2}$ atmospheres, J. Atmos. Sci., 28 , 847-858, 1971 .

DeMore, W. B., and M. Patapoff, Temperature and pressure dependence of $\mathrm{CO}_{2}$ extinction coefficients, J. Geophys. Res., 77, 6291-6293, 1972.

DeMore, W. B., S. P. Sander, D. M. Golden, M. J. Molina, R. F. Hampson, M. J. Kurylo, C. J. Howard, and A. R. Ravishankara, Chemical Kinetics and Photochemical Data for Use in Stratospheric Modeling, JPL Publ. 90-l, 1990.

Gershenzon, Y. M., and A. P. Purmal, Heterogeneous processes in the Earth's atmosphere and their ecological consequences, Russ. Chem. Rev., $59,1007-1023,1990$.

Gershenzon, Y. M., A. V. Ivanov, S. I. Kucheryavyi, and V. B. Rozenshtein, Annihilation of $\mathrm{OH}$ radicals on the surfaces of substances chemically similar to atmospheric aerosol particles, Kinet. Katal., 27, 1067-1074, 1986.

Hampson, R. F., Chemical kinetics and photochemical data sheets for atmospheric reactions, Rep. FAA-EE-80-17, U.S. Dep. of Trans., FAA Office of Environ. and Energy, High Altitude Pollut. Program, Washington, D. C., 1980.

Hanson, D. R., J. B. Burkholder, C. J. Howard, and A. R. Ravishanhara, Measurement of $\mathrm{OH}$ and $\mathrm{HO}_{2}$ radical uptake coefficients on water and sulfuric acid surfaces, J. Phys. Chem., 96, 4979-4985, 1992.

Howard, C. J., Kinetic measurements using flow tubes, J. Phys. Chem., 83, 3-9, 1979.

Huguenin, R. L., R. G. Prinn, and M. Maderazzo, Mars: Photodesorption from mineral surfaces and its effects on atmospheric stability, Icarus, 32, 270-298, 1977.

Hunten, D. M., Aeronomy of the lower atmosphere of Mars, Rev. Geophys.,
$12,529-535,1974$.

Jakosky, B. M, and C. B. Farmer, The seasonal and global behavior of water vapor in the Mars atmosphere: Complete global results of the Viking atmospheric water detector experiment, J. Geophys. Res., 87, 2999-3019, 1982.

Jech, D. D., P. G. Easley, and B. B. Krieger, Kinetics of reactions between free radicals and surfaces (aerosols) applicable to atmospheric chemistry, in Heterogeneous Atmospheric Chemistry, Geophys. Monogr. 26, edited by D. R. Schryer, 107-121, AGU, Washington, D. C., 1982.

Kahn, R., Ice haze, snow, and the Mars water cycle, J. Geophys. Res., 95, $14,677-14,693,1990$.

Kong, T. Y., and M. B. McElroy, Photochemistry of the Martian atmosphere, Icarus, 32, 168-189, 1977.

Krasnopolsky, V. A., Photochemistry of the Martian atmosphere (mean conditions), Bull. Am. Astron. Soc., 23, 1212, 1991.

Leu, M-T., Laboratory studies of sticking coefficients and heterogeneous reactions important in the Antarctic stratosphere, Geophys. Res. Lett., 1S, 17.20, 1988.

Leu, M-T., J. E. Blamont A. D. Anbar, L. F. Keyser, and S. P. Sander, Adsorption of $\mathrm{CO}$ on water-ice and oxide surfaces: Implications for the Martian atmosphere, J. Geophys. Res., 97, 2621-2627, 1992.

Lewis, B. R, and J. H. Carver, Temperature dependence of the carbon dioxide photoabsorption cross section between 1200 and $1970 \AA$, J. Quant. Spectrosc. Radiat. Transfer, 30, 297-309, 1983.

Lin, C. L., and M.-T. Leu, Temperature and third-body dependence of the rate constant for the reaction $\mathrm{O}+\mathrm{O}_{2}+\mathrm{M} \rightarrow \mathrm{O}_{3}+\mathrm{M}$, Int. J. Chem. Kinet., 14, 417.434, 1982.

Lindner, B. L., Ozone on Mars: The effects of clouds and airborne dust, Planet. Space Sci., 36, 125-144, 1988.

Margitan, J. J., Gas Phase Reactions of OH Radicals Studied by Molecular Resonance, Ph.D. thesis, Univ. of Pittsburgh, Pittsburgh, Pa., 1976.

McElroy, M. B., Mars: An evolving atmosphere, Science, 175, 443-445, 1972.

McElroy, M. B., and T. M. Donahue, Stability of the Martian atmosphere, Science, 177, 986-988, 1972.

Michelangeli, D. V., M. Allen, and Y. L. Yung, Heterogeneous reactions with $\mathrm{NaCl}$ in the El Chichon volcanic aerosols, Geophys. Res. Lett., 18, 673-676, 1991.

Michelangeli, D. V., O. B. Toon, R. M. Haberle, and J. B. Pollack, Numerical simulations of the formation and evolution of water-ice clouds in the Martian atmosphere, Icarus, in press, 1993.

Molina, M. J., T. L. Tso, L. T. Molina, and F. C. Y. Wang, Antarctic stratospheric chemistry of chlorine nitrate, hydrogen chloride, and ice: Release of active chlorine, Science, 238, 1253-1257, 1987.

Morris, R. V., J. L. Gooding, H. V. Lauer, Jr., and R. B. Singer, Origins of Marslike spectral and magnetic properties of a Hawaiian palagonitic soil, J. Geophys. Res., 95, 14,427-14,434, 1990.

Mount, G. H., and G. J. Rottman, The solar absolute spectral irradiance 1150-3173 A: 17 May 1982, J. Geophys. Res., 88, 5403-5410, 1983.

Mozurkewich, M., P. H. McMurry, A. Gupta, and J. G. Calvert, Mass accommodation coefficient for $\mathrm{HO}_{2}$ radicals on aqueous particles, $J$. Geophys. Res., 92, 4163-4170, 1987.

Nair, H. A., M. Allen, and Y. L. Yung, Regulation of $\mathrm{CO}$ and $\mathrm{O}_{2}$ abundance by the escape of oxygen and hydrogen in the atmosphere of Mars, Bull. Am. Astron. Soc., 23, 1991.

Nair, H. A., M. Allen, Y. L. Yung, and R. T. Clancy, Martian atmospheric chemistry during the time of low water abundance, MSATT Workshop on the Evolution of the Martian Atmosphere, LPIContrib. 787, Lunar Planet. Inst., Houston, Tex., 1213, 1992.

Parisot, J.-P., and J.-M. Zucconi, Temperature effect on the photodissociation rates in the atmospheres of Mars and Venus, Jcarus, 60, 327-331, 1984.

Parkinson, T. M., and D. M. Hunten, Spectroscopy and aeronomy of $\mathrm{O}_{2}$ on Mars, J. Atmos. Sci., 29, 1380-1390, 1972.

Pinet, $P$., and $S$. Chevral, Spectral identification of geological units on the surface of Mars related to the presence of silicates from Earth-based near-infrared telescopic charge-coupled device imaging, J. Geophys. Res., 95, 14,435-14,446, 1990.

Rozhenshtein, V.B., Gershenzon, Y. M., Ilin, S. D., Kishkovich, O. P., Malkhasyan, R. T., Study of reactions of $\mathrm{HO}_{2}$ radicals by means of combined electron-spin-resonance LMR spectrometer - Destruction on surface. Kinet. Katal., 26, 460-466, 1985.

Seiff, A., Post-Viking models for the structure of the summer atmosphere of Mars, Adv. Space Sci., 2, 3-17, 1982.

Shimazaki, T., Photochemical stability of $\mathrm{CO}_{2}$ in the Martian atmosphere: Reevaluation of the eddy diffusion coefficient and the role of water vapor, J. Geomagn. Geoelectr., 4l, 273-301, 1989. 
Smith, W. V., The surface recombination of $\mathrm{H}$ aloms and $\mathrm{OH}$ radicals, $J$. Chem. Phys., /1, 110, 1943.

Thrush, B. A., Reactions of hydrogen atoms in the gas phase, Prog. React. Kinet., 3, 63-95, 1965.

Tolber, M. A., M. J. Rossi, and D. M. Golden, Antarctic ozone depletion chemistry: Reactions of $\mathrm{N}_{2} \mathrm{O}_{5}$ with $\mathrm{H}_{2} \mathrm{O}$ and $\mathrm{HCl}$ on ice surfaces, Science, 240, 1018-1021, 1988.

Torr, M. R., and D. G. Torr, Ionization frequencies for solar cycle 21: Revised, J. Geophys. Res., 90, 6675-6678, 1985.

Tsang, W., and R. F. Hampson, Chemical kinetic data base for combustion chemistry, Part 1, Methane and related compounds, J. Phys. Chem. Ref. Data, 15, 1087-1279, 1986.

Wood, B. J., and H. Wise, The kinetics of hydrogen atom recombination on pyrex glass and fused quartz, J. Phys. Chem., 66, 1049-1053, 1962.

Yung, Y. L., and W. B. DeMore, Photochemistry of the stratosphere of Venus: Implications for atmospheric evolution, Jcarus, 51, 199-247, 1982.

Yung, Y. L., T. Y. Strobel, T. Y. Kong, and M. B. McElroy, Photochemistry of nitrogen in the Martian atmosphere, Icarus, 30, 26-41, 1977.

Yung, Y. L., J. S. Wen, J. P. Pinto, M. Allen, K. K. Pierce, and S. Paulson, HDO in the Martian atmosphere: Implications for the abundance of crustal water, Icarus, 76, 146-159, 1988.

A. D. Anbar, H. A. Nair, and Y. L. Yung, Division of Geological and Planetary Sciences, California Institute of Technology, Pasadena, CA 91125.

M-T. Leu, Earth and Space Sciences Division, Jet Propulsion Laboratory, California Institute of Technology, Pasadena, CA 91109.

(Received February 3, 1992;

revised November 13, 1992;

accepted January 14, 1993.) 